\title{
BMJ Open What are the contextual risk factors for low colorectal cancer screening uptake in El Paso County, Texas? Spatial cross- sectional analysis
}

\author{
Jennifer Salinas (D) , J Jacquelyn Brito, ${ }^{2}$ Cheyenne Rincones, ${ }^{1}$ Navkiran $\mathrm{K}_{\text {Shokar }}{ }^{1}$
}

To cite: Salinas J, Brito J, Rincones C, et al. What are the contextual risk factors for low colorectal cancer screening uptake in El Paso County, Texas? Spatial crosssectional analysis. BMJ Open 2020;10:e038342. doi:10.1136/ bmjopen-2020-038342

- Prepublication history for this paper is available online. To view these files, please visit the journal online (http://dx.doi. org/10.1136/bmjopen-2020038342).

Received 09 March 2020 Revised 05 August 2020 Accepted 19 August 2020

Check for updates

(C) Author(s) (or their employer(s)) 2020. Re-use permitted under CC BY-NC. No commercial re-use. See rights and permissions. Published by BMJ.

${ }^{1}$ Family and Community Medicine, Texas Tech University Health Sciences Center El Paso, El Paso, Texas, USA

${ }^{2}$ Department of Family Medicine, University Medical Center of El Paso, El Paso, Texas, USA

Correspondence to Dr Jennifer Salinas; jennifer.salinas@ttuhsc.edu

\section{ABSTRACT}

Objective This study examines the geographical and socioeconomic factors associated with uptake of colorectal cancer (CRC) screening (colonoscopies or faecal immunochemical test (FIT) testing).

Design Secondary data analysis.

Setting The Against Colorectal Cancer in our Community (ACCION) programme was implemented in El Paso County, Texas, to increase screening rates among the uninsured and underinsured.

Participants We successfully geocoded 5777 who were offered a free colonoscopy or FIT testing kit.

Primary outcome measure Census-tract CRC screening uptake average.

Results Medicare recipient mortality $(\beta=0.409, p$ value $=0.049)$ and $\% 65$ years or older $(\beta=-0.577, p$ value $=0.000$ ) were significant census tract contextual factors that were associated with the prevalence of CRC screening uptake in the geographically weighted Poisson regression. Neither Latino ethnicity nor immigrant concentration were significant predictors of CRC screening uptake in the ACCION programme. Hot spot analysis demonstrated that there was a significant low-value cluster in South Central El Paso. There was a similar hot spot for \% 65 years or older in this same area, suggesting that uptake was lowest in an area that had the highest concentration of older adults.

Conclusion The results from this study revealed not only feasibility of hot spot analysis but also its utility in geographically tracking successful CRC screening uptake in cancer prevention and intervention programmes.

\section{INTRODUCTION}

Screening is the most effective way to prevent incidence of and mortality from colorectal cancer (CRC). ${ }^{1}$ CRC is among the the most common cause of cancer-related deaths among Latinos, yet only about $50 \%$ follow the current recommended screening guidelines. ${ }^{1}$ Barriers to CRC screening in this population are vast. ${ }^{2}$ Those living in the most vulnerable regions are often those with the least resources to prevent or treat cancer. ${ }^{4-14}$ Latino-dominant communities tend to be poorer, have inconsistent access to healthcare

\section{Strengths and limitations of this study}

- Identification of key population-level demographic risk factor for colorectal cancer and possibly other cancer screenings.

- Novel assessment tool for prevention programmes to quickly identify geographical areas that may need improved strategies to increase uptake.

- Limited inference to El Paso County, Texas.

Participants were uninsured.

and have low cancer screening rates. ${ }^{13}$ However, little information is available on contextual factors that may be important to consider as barriers to CRC screening in these communities.

Latinos living in the US-Mexico border region have less access to care and many times need to travel further to receive any healthcare. ${ }^{15}$ There has been some literature that suggests that Latino communities are protected from certain diseases because of the social support that alleviates some barriers to care or reinforces healthier lifestyle habits such as smoking or drug use. ${ }^{16}$ However, there is also broad literature on cancer misconceptions among Latinos that may be intensified in communities where Latinos are the dominant group. ${ }^{17}$ Nevertheless, these barriers have not been fully examined in Latino-dominant communities like those on the US-Mexico border.

Most studies that have investigated CRC or any cancer screening uptake have done so in metropolitan areas where services are more accessible or in ethnically diverse communities where Latinos are the minority. ${ }^{18}$ Latinos on the US-Mexico border are the least likely to be screened for cancer, ${ }^{19}$ and while we have documentation of individual-level factors that serve as barriers, ${ }^{3}$ little is known about which contextual factors may also serve as important barriers. An examination of context in Latino 
majority communities could provide important clues to why Latinos who live in ethnic communities or poverty may be more likely to develop CRC or are diagnosed at later stages and subsequently more likely to die from the disease.

In this study, we take advantage of a unique dataset to assess how contextual factors are associated with CRC screening uptake in low-income, uninsured Latinos living along the Texas-Mexico border. The Against Colorectal Cancer in our Community (ACCION) programme was implemented in El Paso County, Texas, to increase CRC screening rates among the uninsured and underinsured by offering free education, transportation, screening and navigation services. ${ }^{20}{ }^{21}$ First, we examine the geographical distribution of CRC screening uptake by census tract within El Paso County, Texas. Second, we examine census tract-level population characteristics and access to care to disentangle the influence of each on CRC screening uptake. It is anticipated that despite free access to CRC screening and assistance with logistical barriers, geographical differences in uptake will persist. It is also expected that since the ACCION programme addresses logistical barriers to screening, observed geographical differences will be explained by population characteristics rather than access to care.

\section{METHODS}

\section{Study design}

This is a secondary data analysis of ACCION participant CRC screening uptake data that were aggregated and merged with US Census Bureau tract data.

\section{Patient and public involvement}

A community advisory board was established prior to implementation of the ACCION programme. The board consisted of patient-represented organisations such as clinics and hospitals, special interest groups, such as the American Cancer Society, and other community-based organisations. The board provided the programme team input on recruitment and educational material. Some members of the board also represented hospital partners who performed colonoscopies.

\section{Study population and setting}

ACCION is a CRC prevention and early detection programme that provided no cost education, navigation and CRC screening funded by the Cancer Prevention and Research Institute of Texas between March 2012 and March 2015. The purpose of ACCION is to address the major health disparity of low CRC screening among Latino populations. As part of the ACCION programme, eligible participants were offered a home faecal immunochemical test (FIT) for average-risk individuals and colonoscopy for high-risk individuals. Risk assessment was based on family history in a first-degree relative or prior history of adenomatous polyps. Participants who had either or both were offered the colonoscopy. All participants were recruited from the community through partner agencies (hospitals, clinics and social service agencies) or health fairs. All participants were eligible for the education component of the programme; however, only uninsured age-eligible participants $(50+$ years $)$ were offered screening. For this analysis, we include only data on participants from Phase 1 of the programme - ACCION 1. Additionally only participants who had an address that was successfully geocoded were included in this analysis. In the screening arm of ACCION, there were a total of 8284 participants. However, not all participants had addresses that we were able to geocode. As a result, the final sample size used for this analysis was 5777. Results from this study will be distributed to the community through our community advisory board.

\section{Measurement \\ CRC screening uptake}

Uptake outcomes were recorded on all patients offered either FIT kits or colonoscopies. Successful completion of screening was coded as ' 1 ' if completed and ' 0 ' if otherwise.

\section{Census tract measures}

US Census Bureau data

The sociodemographic census tract measures were downloaded from the US Bureau's website for 161 census tracts for El Paso County, Texas. Data that were selected came from the 2015 American Community Survey estimates, ${ }^{22}$ which were the closest time point to when the ACCION data were collected.

\section{Primary census tract sociodemographic measures}

The primary measures of interest included were census tract poverty prevalence and proportion of the census tract who report as being of Hispanic or Latino ethnicity. $\%$ Poverty was therefore measured as the estimated percentage of individuals living at or below the poverty line in a given census tract. Similarly, \% Hispanic was measured as the estimated percentage of individuals within a census tract that are of Hispanic or Latino ethnicity.

\section{Secondary census tract sociodemographic measures}

Secondary sociodemographic measures include proportion immigrant, high school graduation, total census tract population size and proportion of the census tract that is 65 years and older. First, \% immigrant was measured as the per cent of individuals who report being born in a country other than the USA in a given census tract. High school graduates was measured as per cent of adults 25 years and older with at least a high school diploma in a given census tract. Total population was the total number of residents who inhabited a given census tract. Finally, \% 65 years or older was the percentage of individuals in a given census tract that were 65 years or older. 


\section{Health Resources and Service Administration (HRSA) data}

Data on mortality and primary care access was aggregated by HRSA using Centers for Medicare \& Medicaid Services claims data from $2010 .^{23}$ The 2010 data were the most current time point at the time of the analysis and the closest to the time in which the ACCION data were collected. These data are publically available and were aggregated to a census tract level. Data from this resource were used to detect potential health access disparities that might be associated with CRC screening uptake in ACCION participants. For this analysis, we used mortality prevalence and number of primary care physicians (PCPs) in a given census tract. Cumulative mortality proportion was measured as the percentage of Medicare recipients who died within a given census tract. Number of PCPs was determined to be the number of PCPs within a given census tract.

\section{Analytical approach}

A total of 5777 participant addresses were successfully geocoded using the US Census Bureau Geocoder. ${ }^{24}$ Addresses were matched with respective census tracts and then removed from the overall dataset to protect confidentiality. Census tract screening prevalence was determined by the total number of completions divided by the total number of tests offered. Hot spot analysis using ArcGIS was first performed using census tract-level count of screening completions. A z-score and associated $p$ value were generated using Getis-Ord General G analysis. Geographically weighted Poisson regression for screening completion was then performed to determine if there were significant differentials in uptake by census tract sociodemographic characteristics. This analysis was adjusted for total number of FIT tests or colonoscopy referrals given. In addition, a quadratic equation for poverty was tested, and because of its significance, it was graphed using STATA V.14 ME. ${ }^{25}$

\section{RESULTS}

Table 1 presents overall characteristics of El Paso County. Census tract population size was on average 5000 people but ranged from 626 to as high as 24316. Approximately, $83 \%$ of the county was of Hispanic origin, ranging from $21 \%$ to $100 \%$. On average, about $26.2 \%$ of El Pasoans live at or below the poverty line, and about $71 \%$ have graduated from high school. On average, $11.2 \%$ of El Paso is 65 years or older, ranging from as low as $0.16 \%$ to as high as $24.0 \%$. Finally, about $4.7 \%$ of Medicare recipients died in 2010 (the year of data collection), and there were 2.2 PCPs per census tract, again ranging widely from 0 to 53 .

Geographically weighted Poisson regression results presented in table 2 in rate ratios. Results indicate that Medicare recipient cumulative mortality and $\% 65$ years or older were census tract contextual factors that were associated with the prevalence of CRC screening uptake. Beginning with Medicare recipient cumulative mortality, higher recipient cumulative mortality was associated with
Table 1 El Paso County population characteristics

\begin{tabular}{lccr}
\hline \multirow{2}{*}{$\begin{array}{l}\text { Census tract } \\
\text { measure }\end{array}$} & Mean & Min & Max \\
\cline { 2 - 4 } & 5168.45 & 626 & 24316 \\
\hline Total population & 83 & 21 & 100 \\
$\begin{array}{l}\text { \% Hispanic } \\
\text { \% Poverty }\end{array}$ & 26.2 & 4 & 68 \\
\hline $\begin{array}{l}\text { \% High school } \\
\text { graduate }\end{array}$ & 71 & 20 & 97 \\
$\begin{array}{l}\text { \% 65 years or older } \\
\text { Medicare recipient }\end{array}$ & 11.2 & 0.16 & $24 \%$ \\
$\begin{array}{l}\text { mortality prevalence } \\
\text { (\%) }\end{array}$ & & & \\
$\begin{array}{l}\text { Average number } \\
\text { of primary care } \\
\text { physicians per census } \\
\text { tract }\end{array}$ & 4.7 & 0 & 12 \\
\hline
\end{tabular}

a higher census tract prevalence of CRC screening uptake in ACCION participants $(1.50,95 \%$ CI 1.00 to 2.26). In addition, for every $1 \%$ increase in the population who was over the age of 65 years, the rate ratio for CRC screening decreased by 0.562 (95\% CI 0.421 to 0.750 ). The variable is $\%$ high graduates among those 25 years and older, which includes high school graduates, is also worthy to note (1.16, 95\% CI 0.995 to 1.35$)$, and as would be expected, a higher proportion of high school graduates were associated with higher census tract prevalence of CRC screening uptake among ACCION participants.

Figure 1 illustrates results for CRC screening uptake. In sum, there was a greater uptake of CRC screening in the northern parts of El Paso County and the lowest uptake occurred in South Central El Paso, which borders Mexico. To further explore potential coexisting geographical

Table 2 Geographically adjusted regression results for faecal immunochemical test or colonoscopy screening completion in the Against Colorectal Cancer in our Community study

\section{Coefficient to \\ ratio $\quad 95 \% \mathrm{Cl}$}

\begin{tabular}{lll}
$\begin{array}{l}\text { Medicare recipient } \\
\text { cumulative mortality } \\
\text { proportion (2010) }\end{array}$ & 1.50 & 1.00 to 2.26 \\
$\begin{array}{l}\text { Number of primary care } \\
\text { physicians }\end{array}$ & 0.999 & 0.998 to 1.00 \\
$\begin{array}{l}\text { Poverty } \\
\text { \% 25years+high school }\end{array}$ & 0.001 & 0.881 to 1.12 \\
$\begin{array}{l}\text { graduates } \\
\text { Total population }\end{array}$ & 1.16 & 0.995 to 1.35 \\
\% 65+ & 0.999 & 0.999 to 1.00 \\
\% Immigrant & 1.03 & 0.421 to 0.750 \\
\% Hispanic & 1.04 & 0.868 to 1.22 \\
Constant & 1.98 & 0.876 to 1.22 \\
\hline
\end{tabular}






Figure 1 Colorectal cancer uptake hot spots.

patterns between CRC uptake and Medicare recipient mortality, high school graduation rates and proportion 65 years and older, hot spot analysis was conducted for each individual covariate. Beginning with per cent of residents over the age of 65 years, in figure 2, the highest concentration (hot spots) of adults over the age of 65 years was also in South Central El Paso, where we observed the largest CRC screening uptake cold spot. Similarly, the largest hot spot of Medicare recipient mortality (figure 3) occurs in the same geographical area of the 65 years or older hot spot and CRC screening uptake cold spot. Finally, a hot spot analysis was included for $\%$ high school graduation (figure 4) because of its association in the regression analysis. What the analysis reveals were two distinct cold spots and three distinct hot spots. One of the two cold spots overlaps with the CRC screening uptake cold spot.

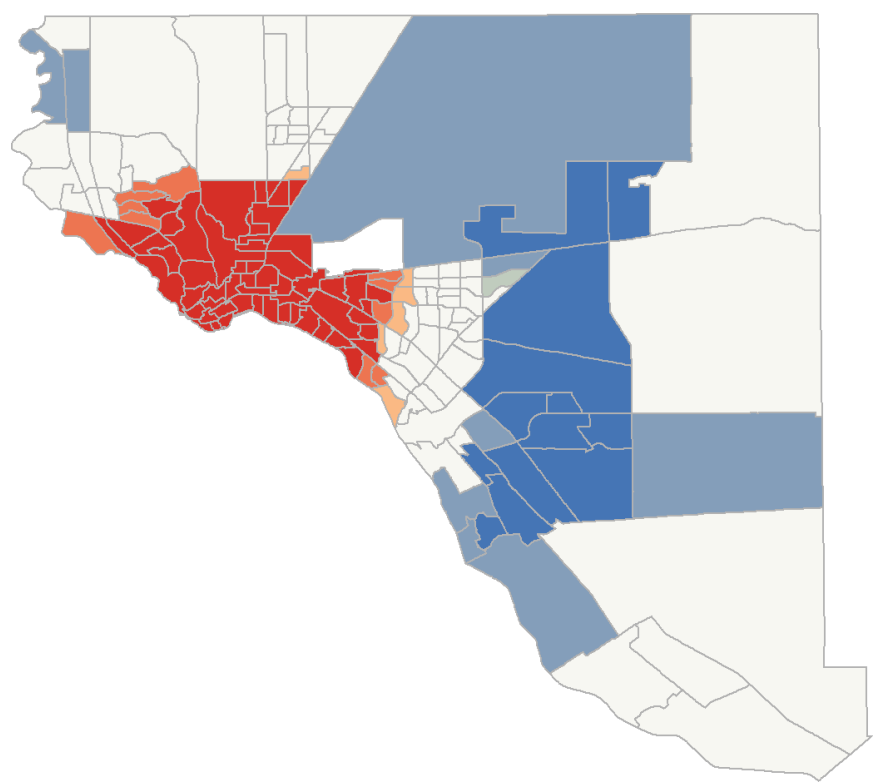

Figure $2 \%$ 65+, 2010 census.



Figure 3 Medicare recipient mortality hot spots.

\section{DISCUSSION}

The purpose of this study was to assess the relationship between census tract-level context and census tract prevalence of CRC screening uptake in ACCION, a prevention programme targeted at low-income and uninsured Latinos living in El Paso County, Texas. Much of the knowledge on screening uptake in Latinos comes from urban areas where they are a minority groups. Additionally, access to care is a documented barrier to cancer screening in Latino groups largely due to lack of insurance coverage or availability of medical care. The ACCION programme was a CRC screening programme that provided education, navigation and free FIT or colonoscopy screening to uninsured residents in El Paso County, Texas. By taking advantage of the ACCION data, we were able to assess geographical patterns of CRC screening uptake among Latinos who participated



Figure 4 High school graduation hot spots. 
in a screening intervention programme. The few studies that have investigated geographical or contextual factors with respect to CRC uptake have done so in other populations, used clinical data or have done so as part of a large cancer incidence or mortality surveillance programme. ${ }^{26} 27$ Therefore, the current study provides a novel approach to assessing screening and other similar prevention programmes in Latinos and other groups.

Studies that have attempted to shed light on Latino cancer disparities have largely been conducted in contexts where Latinos are the minority and access to care is not a barrier. Results revealed that neither Latino ethnicity nor immigrant concentration was a significant predictor of CRC screening uptake in the ACCION programme. These findings suggest that cancer screening and late diagnoses may be associated with other factors that are correlated with ethnic or immigrant concentration in communities where Latinos are the minority. The vast majority of studies that have investigated barriers or facilitators among Latino groups have done so at an individual level. ${ }^{28}$ Most of these studies have identified barriers related to access or misconceptions as the main obstacle to CRC screening. ${ }^{20}{ }^{29-31}$ Few studies have investigated the relationship between ethnic group concentration and health outcomes or cancer screening uptake, generally finding a negative effect of ethnic minority concentration and screening for any cancer. ${ }^{32}$ Information on the effect of Latino ethnic concentration is limited; however, one similar intervention study for breast cancer screening among Latina immigrants in Washington State found a significant beneficial effect of higher ethnic concentration on screening uptake. ${ }^{33}$ These inconsistencies by outcome, race/ethnicity and region illustrate the need for further investigation to best identify prevention programming, depending on the community context.

\section{Age distribution}

An increase in census tract concentration of older adults was associated with a lower prevalence of CRC screening uptake among ACCION participants. In both the regression and hot spot analysis, higher census tract concentration of older adults (65 years or older) was significantly associated with lower CRC screening uptake in the ACCION programme. The largest cold spot of uptake was located in one of the oldest, more traditional areas of El Paso. There is little to no information on the impact of older adult communities on screening or general preventive care. While there are specialised retirement communities for more affluent adults that may provide actual assistance to older adults to assure preventive care compliance, ${ }^{34}$ the majority of older adults live on fixed incomes and live in communities with limited resources. ${ }^{35}$ Furthermore, as the older adult population grows in size with the ageing baby boomers, neighbours that are primarily 65 years or older may become the norm. Despite these demographic trends, there are few studies to compare the results from this study to. Most studies that have assessed health and well-being of older adults in older-aged communities, have done so in communities where participants were of affluence or were institutionalised or lived outside of the
USA. ${ }^{36}$ It is well documented that older Latinos tend to live in a community environment longer, making use of family and other social support resources to assist with healthcare needs. ${ }^{37}$ Little is known as to how these older communities may serve as barriers or facilitators to health information. The findings from this study could suggest generational influences of cancer screening knowledge or fear that may be more common in older communities, where correct knowledge may not be as available as in areas that have a more diverse age distribution. More information is needed to understand how population demographics, such as age, may impact the exchange of health information and screening behaviours in order to better reach those living in older adult communities to ensure timely CRC screening to prevent incidence and late-stage diagnosis.

Previous research on cancer screening suggests better screening is associated with increased access to healthcare. This study differs from most in that analyses of these relationships were aggregated to a census tract level. Unlike the other individual-level studies, however, findings indicated that there may not be as strong of a relationship with census tract average CRC screening uptake and census tract healthcare provider access in this study. Participants in ACCION were given free screening and transportation to appointments, thereby eliminating logistical barriers to successful screening completion. It may be that when aggregating data as done in this study, these logistical barriers become less significant as may be the case among individuals. However, physician practices were not evenly distributed across the county, and therefore, the estimates may not be as stable as in other previous studies. This is an area that needs further investigation, since previous studies to compare are lacking at this level of analysis.

While this study provides novel information on contextual influences on CRC screening uptake in Latinos, there are important limitations to consider. First, only residents who were uninsured were eligible to participate in ACCION. This could potentially be problematic in the interpretation of the results from this study, since the participants are selected into the programme because of their socioeconomic status, which includes insurance. Therefore, these findings would need to be repeated among insured and underinsured residents to determine if the significant relationships are consistent across population subgroups within this larger Latino community. Additionally, while the homogeneity of ethnic representation is a strength to disentangle mechanisms that may be responsible for CRC screening in Latinos, El Paso is a US-Mexico border community that is mostly populated with those of Mexican origin. Additionally, given the proximity of El Paso to Mexico, many who were offered screening may already be receiving care in Mexico, which has been documented elsewhere. ${ }^{38}$ Findings would need to be repeated in other Latino groups and in other parts of the USA to determine contextual nuances that may create variation between locations and ethnic subgroups. Finally, these data are cross-sectional and participants were only followed up for a limited time period, so therefore it is unknown if participants who refused eventually followed through with CRC screening. 


\section{CONCLUSIONS}

Despite potential limitations, this study provides new findings on contextual barriers to CRC screening in a largely Latino community. Hot spot analysis is an effective way to understand the distribution of disease and prevention behaviours in smaller geographical scales such as within a county or city. While typically used in cancer research to detect cancer clusters ${ }^{39}$ the results from this study revealed not only feasibility but also its utility in geographically tracking successful CRC screening uptake in an intervention programme. Using hot spot analysis for CRC and other cancer screening could provide health systems and public health departments realtime information on cancer prevention behaviour within their community. This could lead to improved responsiveness to public health needs, as well as inform outreach and education efforts to improve screening.

Contributors JS conducted analysis and primary author of the paper. JB contributed to literature review, writing and editing the final draft of the paper. CR contributed to writing and editing final draft of the paper. NKS is the principal investigator on the ACCION study, provided the data to JS and helped with writing and editing the final draft of the paper.

Funding This study was funded by the Cancer Prevention and Research Institute of Texas (grant number PP140164).

Map disclaimer The depiction of boundaries on this map does not imply the expression of any opinion whatsoever on the part of BMJ (or any member of its group) concerning the legal status of any country, territory, jurisdiction or area or of its authorities. This map is provided without any warranty of any kind, either express or implied.

Competing interests None declared.

Patient and public involvement Patients and/or the public were not involved in the design, conduct, reporting or dissemination plans of this research.

Patient consent for publication Not required.

Ethics approval ACCION was approved by the institutional review board at Texas Tech University Health Sciences Center El Paso.

Provenance and peer review Not commissioned; externally peer reviewed.

Data availability statement Data are available upon reasonable request. Data are not in a repository and access requests can be made to NKS at navkiran.shokar@ ttuhsc.edu.

Open access This is an open access article distributed in accordance with the Creative Commons Attribution Non Commercial (CC BY-NC 4.0) license, which permits others to distribute, remix, adapt, build upon this work non-commercially, and license their derivative works on different terms, provided the original work is properly cited, appropriate credit is given, any changes made indicated, and the use is non-commercial. See: http://creativecommons.org/licenses/by-nc/4.0/.

ORCID iD

Jennifer Salinas http://orcid.org/0000-0001-6276-7184

\section{REFERENCES}

1 American Cancer Society. Cancer Facts \& Figures for Hispanics/ Latinos 2018-2020. Available: https://www.cancer.org/content/ dam/cancer-org/research/cancer-facts-and-statistics/cancer-factsand-figures-for-hispanics-and-latinos/cancer-facts-and-figures-forhispanics-and-latinos-2018-2020.pdf. [Accessed 12 May 2019].

2 Shokar NK, Carlson CA, Weller SC. Factors associated with racial/ ethnic differences in colorectal cancer screening. J Am Board Fam Med 2008;21:414-26.

3 Byrd TL, Calderón-Mora J, Salaiz R, et al. Barriers and facilitators to colorectal cancer screening within a Hispanic population. Hisp Health Care Int 2019;17:23-9.

4 Mojica CM, Flores B, Ketchum NS, et al. Health care access, utilization, and cancer screening among low-income Latina women. Hisp Health Care Int 2017;15:160-5.
5 Tung J, Politis C, Chadder J, et al. Geographic variation in colorectal cancer incidence and the disparities in the prevalence of modifiable risk factors across Canada. J Glob Oncol 2018;4:15s.

6 Feng X, Tan X, Alenzi EO, et al. Spatial and temporal variations of screening for breast and colorectal cancer in the United States, 2008 to 2012. Medicine 2016;95:e5656.

7 Robert SA, Position S. Socioeconomic position and health: the independent contribution of community socioeconomic context. Annu Rev Sociol 1999;25:489-516.

8 Schootman M, Jeffe DB, Baker EA, et al. Effect of area poverty rate on cancer screening across us communities. J Epidemiol Community Health 2006:60:202-7.

9 Henley SJ, Anderson RN, Thomas CC, et al. Invasive center incidence, 2004-2013, and deaths, 2006-2015, in nonmetropolitan and metropolitan Counties - United states. MMWR Surveill Summ 2017;66:1-13.

10 Davis MM, Renfro S, Pham R, et al. Geographic and populationlevel disparities in colorectal cancer testing: a multilevel analysis of Medicaid and commercial claims data. Prev Med 2017:101:44-52.

11 Uphoff EP, Pickett KE, Cabieses B, et al. A systematic review of the relationships between social capital and socioeconomic inequalities in health: a contribution to understanding the psychosocial pathway of health inequalities. Int $J$ Equity Health 2013;12:54.

12 Adler NE, Newman K. Socioeconomic disparities in health: pathways and policies inequality in education, income, and occupation exacerbates the gaps between the health "haves" and "have-nots". Health Affairs 2002;21:60-76.

13 Andrilla CHA, Moore TE, Man Wong K, et al. Investigating the impact of geographic location on colorectal cancer stage at diagnosis: a national study of the seer cancer registry. $J$ Rural Health 2020;36:316-25.

14 Pew Research Center Hispanic Trends. Facts on Latinos in the U.S. Available: https://www.pewresearch.org/hispanic/fact-sheet/latinosin-the-u-s-fact-sheet/\#demographic-characteristics-of-us-hispanicpopulation-2017 [Accessed 24 Nov 2019].

15 Su D, Pratt W, Salinas J, et al. Rural-urban differences in health services utilization in the US-Mexico border region. J Rural Health 2013;29:215-23.

16 Echeverría SE, Pentakota SR, Abraído-Lanza AF, et al. Clashing paradigms: an empirical examination of cultural proxies and socioeconomic condition shaping Latino health. Ann Epidemiol 2013;23:608-13.

17 Jackson E, Hernandez L, Mallett VT, et al. Knowledge, perceptions, and attitudes toward pelvic organ prolapse and urinary incontinence in Spanish-speaking Latinas. Female Pelvic Med Reconstr Surg 2017;23:324-8

18 Castañeda SF, Gallo LC, Nodora J, et al. Colorectal cancer screening among Hispanics/Latinos in the HCHS/SOL sociocultural ancillary study. Prev Med Rep 2019;15:100947.

19 United States-Mexico Border Health Commission. Access and use of health care. Available: https://www.ruralhealthinfo.org/assets/9403105/health-status-in-the-united-states-mexico-border-region.pdf [Accessed 17 Nov 2019].

20 Shokar NK, Byrd T, Salaiz R, et al. Against colorectal cancer in our neighborhoods (ACCION): a comprehensive community-wide colorectal cancer screening intervention for the uninsured in a predominantly Hispanic community. Prev Med 2016;91:273-80.

21 Shokar NK, Byrd T, Lairson DR, et al. Against colorectal cancer in our neighborhoods, a community-based colorectal cancer screening program targeting low-income Hispanics: program development and costs. Health Promot Pract 2015;16:656-66.

22 United States Census Bureau. American FactFinder. Available: https://factfinder.census.gov/faces/nav/jsf/pages/index.xhtml

23 Health and Human Resources and Services Administration (HRSA). Explore data and maps on HRSA's health care programs. Available: https://data.hrsa.gov/

24 United States Census Bureau. United States census bureau Geocoder. Available: https://geocoding.geo.census.gov/

25 Stata corporation. Stata me15. College Station, TX: Stata corporation, 2016.

26 Stracci F, Gili A, Naldini G, et al. Geospatial analysis of the influence of family doctor on colorectal cancer screening adherence. PLOS One 2019;14:e0222396.

27 de Klerk CM, Gupta S, Dekker E, et al. Socioeconomic and ethnic inequities within organised colorectal cancer screening programmes worldwide. Available: https://gut.bmj.com/content/67/4/679.long

28 Gonzalez JJ, Wahab A, Samalik J, et al. Barriers and facilitators of colorectal cancer screening among a Hispanic community in Michigan. J Racial Ethn Health Disparities 2020;7:137-43. 
29 Nagelhout E, Comarell K, Samadder NJ, et al. Barriers to colorectal cancer screening in a racially diverse population served by a safetynet clinic. J Community Health 2017;42:791-6.

30 Fernandez ME, Wippold R, Torres-Vigil I, et al. Colorectal cancer screening among Latinos from U.S. cities along the Texas-Mexico border. Cancer Causes Control 2008;19:195-206.

31 Yepes-Rios M, Reimann JOF, Talavera AC, et al. Colorectal cancer screening among Mexican Americans at a community clinic. Am J Prev Med 2006;30:204-10.

32 Buehler JW, Castro JC, Cohen S, et al. Personal and neighborhood attributes associated with cervical and colorectal cancer screening in an urban African American population. Prev Chronic Dis 2019;16:e118.

33 Molina Y, Plascak JJ, Patrick DL, et al. Neighborhood predictors of mammography barriers among US-based Latinas. J Racial Ethn Health Disparities 2017:4:233-42.

34 King ES, Resch N, Rimer B, et al. Breast cancer screening practices among retirement community women. Prev Med 1993;22:1-19.
35 Janus AL, Ermisch J. Who pays for home care? A study of nationally representative data on disabled older Americans. BMC Health Serv Res 2015;15:301.

36 Stuck AE, Moser A, Morf U, et al. Effect of health risk assessment and counselling on health behaviour and survival in older people: a pragmatic randomised trial. PLoS Med 2015;12:e1001889.

37 Cantu PA, Angel JL. Demography of living arrangements among oldest-old Mexican Americans: evidence from the Hispanic epidemiologic study of the elderly. J Aging Health 2017;29:1015-38.

38 de Heer HD, Salinas J, Lapeyrouse LM, et al. Binational utilization and barriers to care among Mexican American border residents with diabetes. Rev Panam Salud Publica 2013;34:147-54.

39 Amin RW, Fritsch BA, Retzloff JE. Spatial clusters of breast cancer mortality and incidence in the contiguous USA: 2000-2014. J Gen Intern Med 2019;34:412-9. 